\title{
Bridging the Gap: A Collegiate Perspective on the Integration of Research into Practice
}

\author{
Jed Smith \\ Department of Intercollegiate Athletics, University of Northern lowa, Cedar Falls, lowa, \\ United States
}

Sport is a constantly evolving organism in which training methodologies are being shaped and fashioned in real time. The sport industry in recent years has grown into a very lucrative field with great financial elements at stake for those vested around a sport franchise. Winning competitions positively correlates with financial gain for the sport organization as losing negatively impacts the bottom line of the franchise (1). Due to the financial factors and pressures, as well as the spirit of competition, during the course of the history of sport, fringe methodologies in training, recovery, nutrition, sports medicine, sports psychology, and management have persistently been introduced (2). These fringe methodologies evolve out of a relentless attempt for coaches and athletes to gain an advantage on the opposition, not only to aid in the act of winning in the realm of athletic competition, but to gain in the field financial prosperity (3).

Understanding the complexity of these fringe evolutions in methodologies, coaches must sift through endless practices, notions, and philosophies in order to decipher and code their own pathway to success in order to find what is referred to as "Best Practice" (4). This can be overwhelming and confusing to the strength and conditioning professional. To simplify this process, a strength and conditioning coach must rely on empirical evidence.

How should we define empirical evidence? Empirical evidence can be obtained by a variety of means. First, looking at what the scientific literature says. Seeking what has been established in the literature through peer reviewed journals. Second, coaches can look to what highly successful programs have done through time tested methods in which those organizations have put into practice a specific methodology, which has been systematically followed and proven by way of their convincing achievement in sport. Third, coaches can use their own anecdotal deductions and conclusions based on internal analytics measuring effectiveness of programming from their own pool of athletes, comparing results of performances as well as in-house pre and post testing around training protocols or mesocycles throughout a macrocycle, determining which protocols to be superior in desired results (5).

\section{References}

1. De Bosscher, V., Shibli, S., Van Bottenburg, M., De Knop, P., \& Truyens, J. (2010). Developing a method for comparing the elite sport systems and policies of nations: A mixed research methods approach. Journal of Sport Management, 24, 567-600. 
2. Gillett, M. (2014, May). Developing a high performance model in the English Premier League. Could this work in the NBA? Symposium of the 2014 NBA Strength and Conditioning Conference, Chicago Illinois.

3. Batchelor, B. (Ed.). (2011). Cult Pop Culture: How the Fringe Became Mainstream: How the Fringe Became Mainstream. ABC-CLIO

4. Richard, P. J., Devinney, T. M., Yip, G. S., \& Johnson, G. (2009). Measuring organizational performance: Towards methodological best practice. Journal of management, 35(3), 718-804.

5. Collins, J., \& Hansen, M. T. (2011). Great by Choice: Uncertainty, Chaos and Luck-Why some thrive despite them all. Random House. 